\title{
NONSTANDARD CONSTRUCTIONAL SOLUTIONS IN CONTEMPORARY CLOTHING DESIGN
}

\author{
Magdalena Owczarek, Andrzej Nawrot, Małgorzata Łukawska, Aleksandra Wereszka, \\ Łukasz Grzejszczak, Piotr Mastalerz
}

Lodz University of Technology, Faculty of Material Technologies and Textile Design, Institut of Architecture of Textiles, Żeromskiego 116, 90-924 Łódź e-mail:magdalena.owczarek@p.lodz.pl

\begin{abstract}
:
The paper presents the influence of the design process on making the nonstandard patterns-constructional solutions in contemporary clothing design. A few examples of design processes have been presented, differing because of the source of inspiration and individuality of the designer in his or her strive to create original clothing forms. The influence of various factors connected with the development of new constructional solutions in clothing (including social, ideological, resulting from fashion trends, and the impact of the environment) has also been presented.
\end{abstract}

\section{Keywords:}

construction, clothing design

\section{Introduction}

Clothing design is an artistic discipline in which the designer faces the problem of maintaining harmony between aesthetics and functionality of clothing in the context of originality. It is based on careful observation of changes occurring in fashion, from earliest times to the present. An inseparable part of all clothing projects is their construction, which strongly affects the intended utility and aesthetic effect. Over the years, some standards of clothing construction were set, resulting from specific human anatomy. When the body is tightly wrapped with fabric, ease of movement is hindered. Therefore, fabric forms covering the body must contain constructional clearances of various sizes, which ensures freedom of movement for the wearer after assembly. The questions arise: How the design process affects the development of new constructional solutions in clothing? What is most important when changing standard solutions in clothing construction, taking into account diverse utility and aesthetic needs of contemporary consumers?

\section{Design process and changing the standards of clothing construction}

Today, standards of clothing construction are determined by the methods of uniform design for individual types of human figures. They form a set of grids differing in the size of construction accessories suitable for the particular type of clothing. They provide the basis for general-purpose clothing, corresponding to certain ergonomic, functional, utility and quality conditions. Construction standards are subject to periodic changes, because of the influence of fashion trends and as a result of using textiles of different properties [10-12]. While changing standards of clothing construction, it is necessary, however, to take into account the shape of boundary surfaces of the upper and lower body. In case of the upper body, the garment is limited by the lines of the neck, shoulders, armpits, chest, shoulder blades, and upper limbs. For lower body, it is limited by the waist, hips, crotch, and lower limbs. In case of tight-fitting garments, the shape of the boundary surfaces changes-its lower limits are the lines going through the waist, the upper part of the hips, and the abdomen. These areas represent some kind of limitation that should be taken into account in the process of clothing design (Figure 1) [1-7,12].
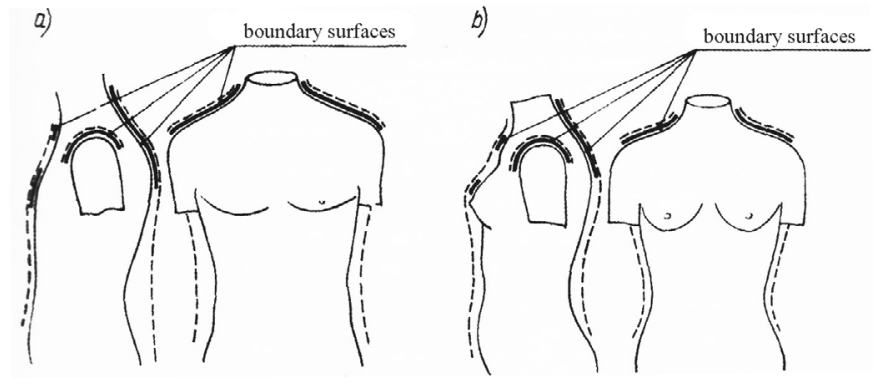

Fig. 1 Boundary surfaces in upper body: (a) male and (b) female [12].

The design process can be systematized into three basic stages: detection and formulation of the problem, generating a solution concept; its verification; and implementation [25]. This process can sometimes be quite complicated, depending on the problem the designer attempts to solve. The creation process covers a certain range of activities including identification of the needs of the potential users and market on which the product is intended to function; determining production quantity 
and maximum prices for the product in relation to technical and technological capabilities of the manufacturer; search for appropriate inspiration; making initial sketches, models, and prototypes; then the production stage; and finally, distribution. Such products should be characterized by previously determined features, to meet the requirements of the user and ensure profits for the producer. These requirements must be defined already at the stage of formulating design assumptions [27]. According to the definition from the dictionary of the Polish language, designing is related to working out the concept of changing reality in a way that allows its implementation by others or technical devices [22]. Searching for solutions to a given problem always involves changing the existing standard condition, regardless of the area of the designer's activity. In the design process, while creating new, original clothing projects, standard constructional solutions are often abandoned. This is due to several factors, including individual predispositions of the designer, inspirations, trends, or ideologies, that have a significant impact on the project [13-20]. The following are some examples of the impact of various factors on the creation of nonstandard constructional solutions in clothing, resulting from the design process.

\section{Utility and aesthetic requirements}

Protective function was the first overriding requirement for clothing. With the development of civilization, apart from this purely utilitarian purpose, symbolic functions expressing the social status of the wearer have become increasingly important [7-9]. It resulted in the need to pay more attention to the overall artistic expression of the product, to whether its form is modest or lavish-to the contained line patterns, textures, colors, materials, and types of finish. This new approach was caused by the changes in social and political relations in Europe, which over the centuries tended to formulate trends in world fashion. Changes in customs, art, and architecture, as well as creative inventions, relating to new technologies and the use of raw materials have also had a great impact. Despite the development of technological capabilities, the form tended to simplify over the centuries, until the process reached its apogee in minimalism. It was also the result of evolution of the factors mentioned earlier. Functionality of form became ideologically overriding, because of the completely different lifestyle of modern people.

\section{Industrial design and fashion design}

To understand industrial design, it is necessary to keep the present in mind and also to understand the past and look forward to the future. Utility design is the result of industry development, including the design of industrial forms. It is a creative activity and a specific field linking disparate issues such as technology, material culture, art, economics, fashion, ecology, sociology, and ergonomics. Initially, artistic activities related only to those areas in which aesthetic parameters such as structure, color, shape, or ornament had a significant impact on the overall assessment of the object by the consumers. Previously, this business sector was described as "decorative art" or "applied art." However, design does not only refer to the external features of the product. It is a concept integrating numerous areas of human activity, going beyond the idea of creating patterns for industrial production.

\section{Examples of changes in construction standards of clothing resulting from the design process, inspired by Scandinavian industrial design and fashion [27-29]:}

Scandinavia is a perfect example of how the form, resulting from ideology, gets converted into a huge commercial success. Scandinavian industrial design, in a very effective way, shapes the aesthetic tastes of an increasing group of customers worldwide. Many publications and institutions attempted to define the term "Scandinavian industrial design." Its essence lies in timeless simplicity, functionality, and high quality of materials. However, its key to success is ideology [27-29]. Advertisements of the leading manufacturers claim that they are "For all who want to live their own way ... Your lifestyle is to suit your own needs, we create for people who want to live ... on their own terms. Our products result from the understanding of human needs. Their task is to facilitate your life. Get inspired with them, match them to your needs and mix styles. It is you who knows best what suits you" [21].

One thing is certain: the Scandinavians undoubtedly deserve to be called the best artists in the field of design. It seems, however, that the concept of Scandinavian fashion is not nearly as widespread as Scandinavian design. Scandinavian clothing is characterized by qualities such as simplicity, sophisticated aesthetics, thought-out functionality, and not very complicated constructions. At the same time, it is enough to take a closer look at the details to notice some new, interesting design solutions. Of course, these are intentional measures that create the interesting, unique whole. We can safely say that this is constructional fashion with a modern twist. One of the most interesting fashion proposals from Scandinavia is COS (Collection of Style) brand. It has been present on the clothing market since 2007 and is one of the companies of $\mathrm{H}$ \& $\mathrm{M}$ consortium. Since it was founded, COS Company has seduced the customers by its own unique style. Swedish company ACNE founded in 1996 is also the pride of Scandinavian fashion. In recent years, it has becomes the "hottest commodity," which the consumers are happy to buy. It is an ideal proposal for those who appreciate good fashion and good design. An example of changes in construction standards of clothing resulting from the design process inspired by Scandinavian industrial design and fashion is shown in Figure 2 [27-29].

\section{Ideologies and social trends in fashion design}

Ideologies stem from the search for values and believes. In this way, different kinds of cultural and social problems arise, which contribute directly to the formation of entire fashion generations. One of such examples is Generation X, whose first representatives was a group of teenagers from the United States. Their nonchalant attitude to the world was misunderstood by the rest of the society. As a result, they 

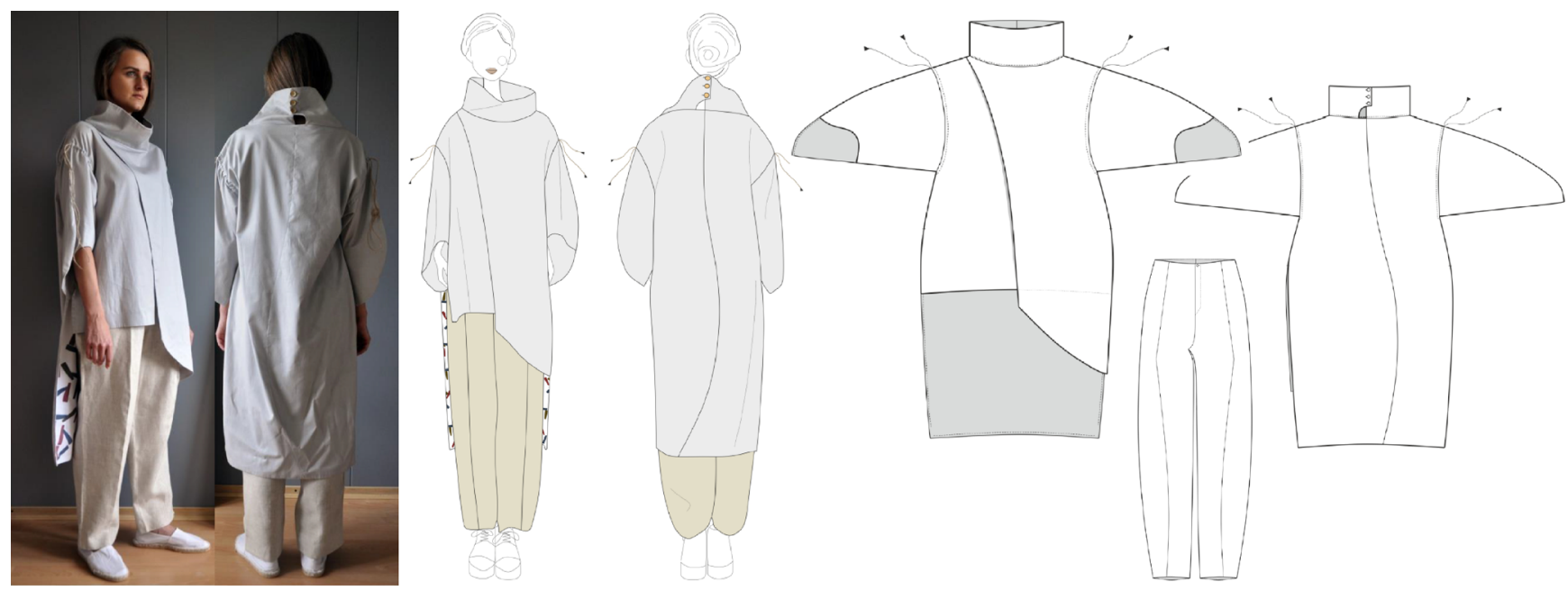

Fig. 2. Examples of clothing with nonstandard constructional solutions inspired by Scandinavian design [29]

were often neglected in interpersonal relations. Their negative attitude to the omnipresent consumerism was badly received by the society. However, such an approach to the world makes you think about who we really are and what should be the most important in life. The representatives of this group often described their image as similar to their idols, but much worse. They wanted to blend into the background of the streets. They were not disturbed by a hole in the trousers or a torn jacket. Generation X was primarily a way of behavior and a way of being, resulting from the social situation in which the young people found themselves. Representatives of the $\mathrm{X}$ generation can also be found in the modern world, regardless of the continent or country. What unites them are the same qualities as before: employment difficulties, fear of the future, and aversion to consumer environment in which they live (Figure 3) [30].

Among the styles based on the visions of the future, postapocalyptic style is one of the most intriguing and extraordinary. It is based on fantasies about the future and conveys a message that makes people aware of the threats posed by human nature. Depending on the scenario, visions of this trend in fashion differ significantly. Strong character of the silhouettes results from visualizing difficult living conditions and readiness for continuous fight for survival. While creating visions of the post-apocalyptic world, we make a kind of experiment. This issue affects many fields of art and is directly connected with the changes that are taking place in present time and strongly influence our future. The biggest impact on our lives is exerted by technological progress, which was considered by futurologists as a possible cause of mankind destruction. Futuristic trend allowed the artists to differently interpret the reality, thanks to which art gained new meaning, that is, it has become more accessible. More attention started to be paid to ergonomics and utility of art. But above all, traditional rules in designing/creating were abandoned, thanks to which the artists could freely experiment with art in search of new forms and methods. The result of these ideas were less standard clothing constructions (Figure 4) [31].

\section{Architecture and clothing}

As history shows us, over the centuries, all sorts of trends or phenomena of the surrounding space, for example, architecture, were a source of inspiration for artists representing different fields of art and culture. Analyzing this fact in terms of fashion design, it can be noticed that inspirations for creating garments were drawn from many disciplines, starting from arts and works
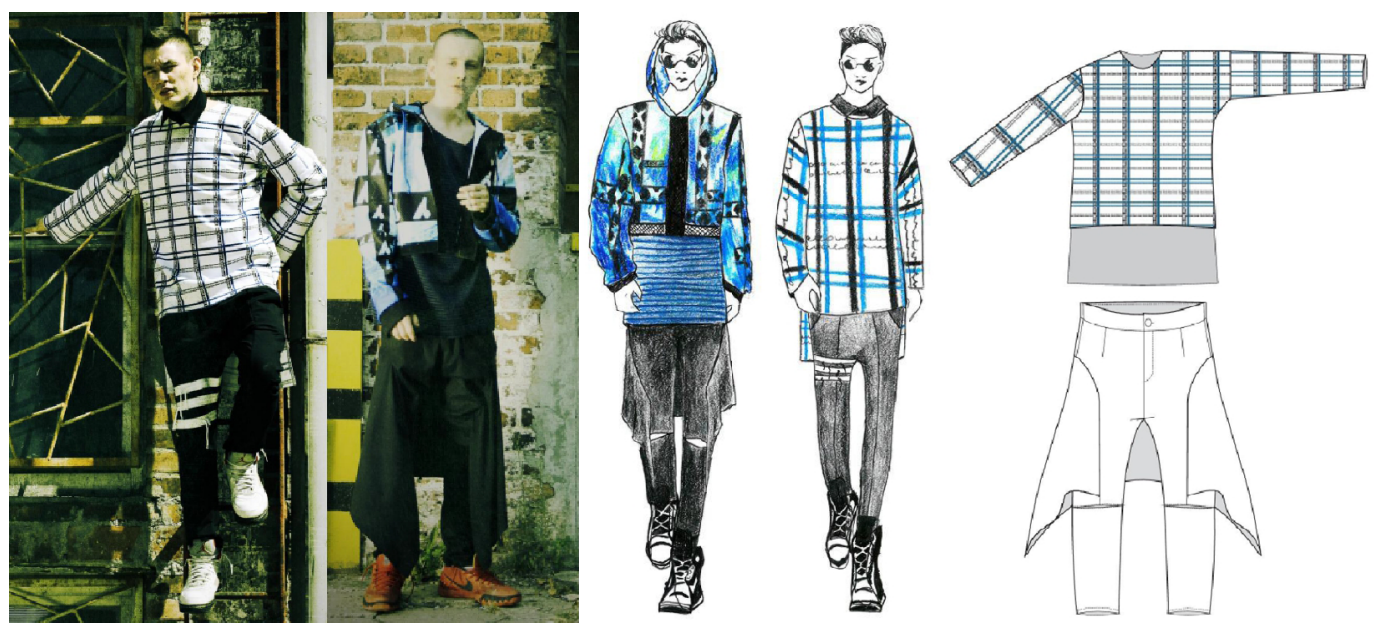

Fig. 3. Example of clothing with nonstandard constructional solutions inspired by ideology of Generation X [30]. 


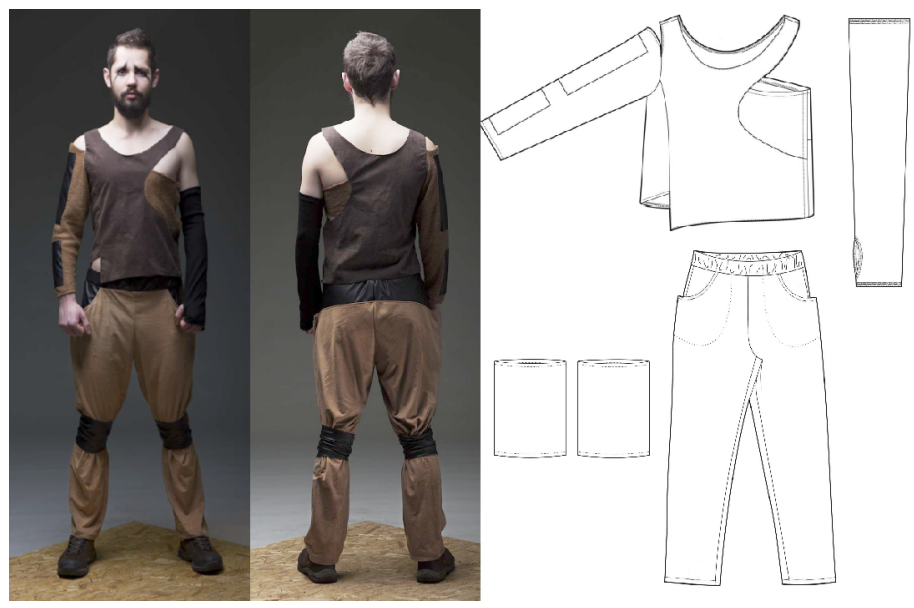

Fig. 4. Example of clothing with nonstandard constructional solutions inspired by futurology [31].

of other authors and ending with more distant fields that are not necessarily associated with the artistic domain, such as technological progress, mechanics, or generally understood science [32]. Combining these remote areas facilitates the creation of nonstandard forms, particularly in premier vision, and pret-a-porter collections. In case of pret-a-porter clothing, design is based on the search for the possibility of synthesizing two different fields: fashion and architecture. Creating a relationship between these two disciplines is possible by finding means of expression that are suitable for fashion and simultaneously reflect the original aesthetics of different architectural projects by Santiago Calatrava, Ludwig Mies van der Rohe, and Zaha Hadid [27,32,33]. The application of form deconstruction, that is a deliberate change in constructional standards, required a lot of trials and calculations, which is particularly evident in Figure $5 \mathrm{a}$. As a result, clothing gained spaciousness and modified nonstandard forms. By using deconstruction and nonstandard forms and materials, it is possible to deform human figure, give it some specific shapes and features, and enhance or mask its advantages and disadvantages [28].

\section{Nature and clothing}

Going back to the world of nature can open multiple perspectives for creating a project that is not only visually attractive but also functional, just like in bionics. After years of admiration for huge metropolis, and living in buildings of steel and concrete, people more and more often escape from the civilization. Those who are more sensitive notice that the world of nature is full of events, full of beauty, and also full of peace. People who managed to preserve this eternal strong bonds with nature subconsciously want to use it for themselves. They want to be fashionable, be "eco," and choose natural materials [30]. Nature can provide numerous inspirations, it's actually as immense as the whole Universe. The analysis combining nature themes in fashion and the same motives in art of photography has become the key to defining the collection. It clearly shows the way of designing. The created photographs became a concrete idea, which was later applied in the collection. Referring to nature in the work of art can disrupt the naturalness or even substantially diverge from the concept of naturality. Surrealistic or abstract photography or clothing design is a distortion of reality. However, surrealism opens artist's mind to a new reality. Nature is a muse that inspires the design of new visions, comprehensive, and going beyond any standard frameworks. Collection shown in Figure 6 has become supernatural because of the use of photographs of nature and nonstandard constructional solutions subordinate to the nature patterns. Perceiving beauty in ugliness makes everything become beautiful. What is most important is the way we understand the world, interpret it, and translate our own feelings into the project, which has to fully reflect this effect. These assumptions led to complete elimination of any standard cuts and clothing forms [30].

However, designing process requires awareness of the burden of responsibility that lies with the creator who treats nature as a source of inspiration but should not pose a threat to it starting from the stage of fabrics selection. The problem of environmental damage is severe. On a global scale, a single person is not able to solve it, but the designer can contribute to its repair by educating and motivating the consumers [30].

\section{Conclusions}

The presented examples of different design processes illustrate the effects of works that take place in the process of writing diploma dissertations. In every case, this process is an experiment for the designer. The visions of changing standard constructional solutions appear with time. The design process, often having its source in inspiration, becomes the main impulse for introducing changes into the standard approach to clothing forms. The more distant the source, the more surprising the effects of these changes can be.

In response to the questions posed in the introduction, it seems clear that the design process has a significant impact on generating new constructional solutions in clothing. It is shaped by various factors, resulting from many aspects such as individuality of the designer, inspiration, trends, and design assumptions. They define the capabilities and limitations: ergonomic, technical, technological, aesthetic, and functional. What is most important in changing standard solutions in 
a)
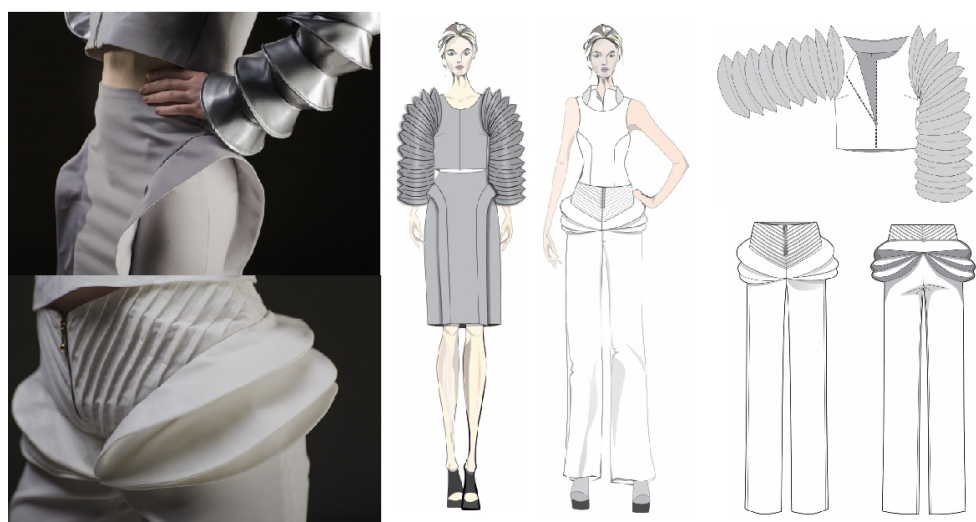

b)
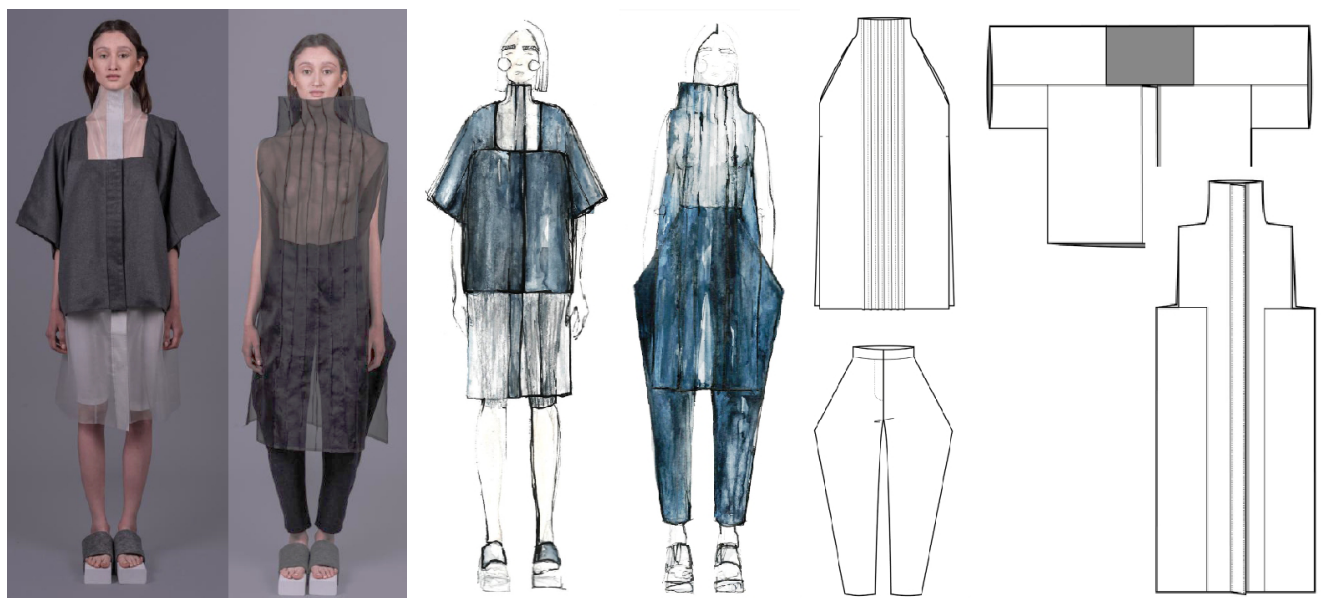

c)

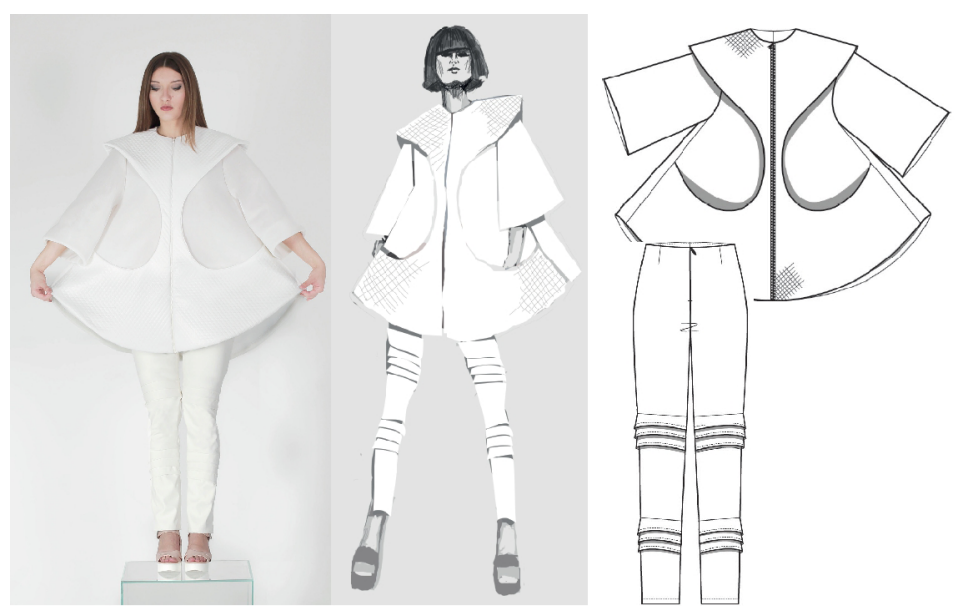

Fig. 5. Example of clothing with nonstandard constructional solutions inspired by (a) futuristic architecture by Calatravy [28], (b) modernist architecture by Ludwiga Miesa van der Rohe [27], and (c) architecture by Zahy Hadid [29].
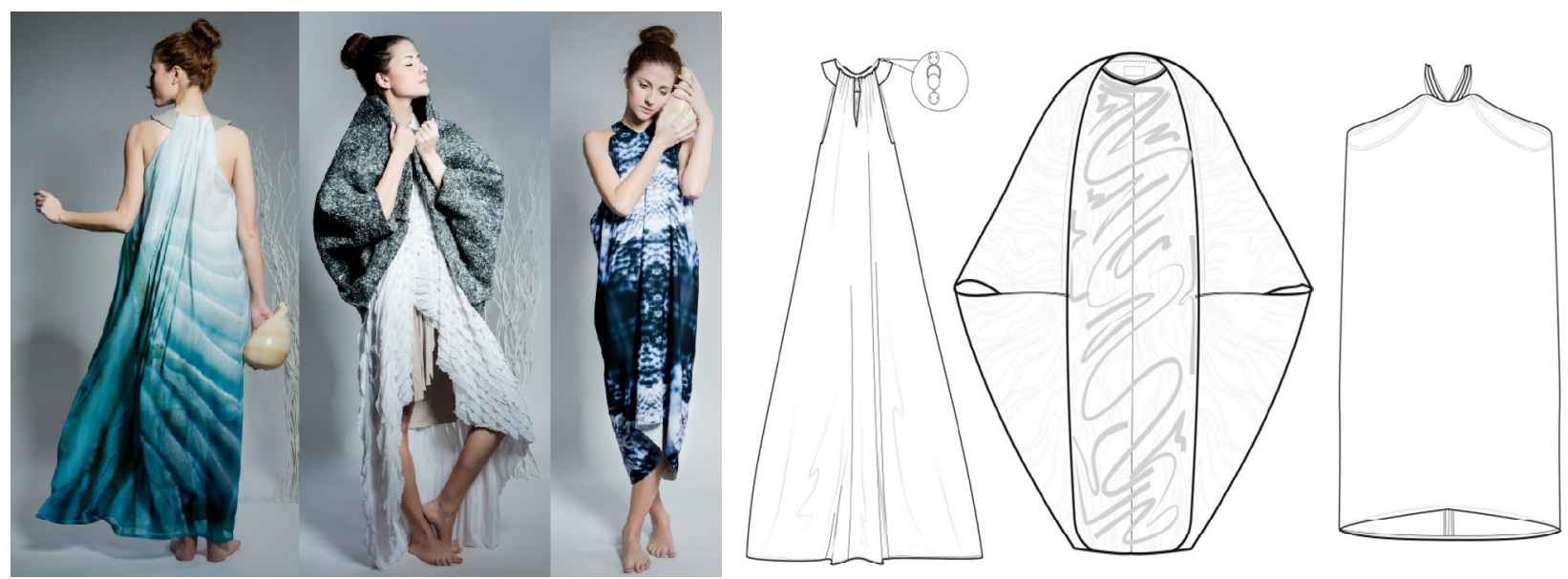

Fig. 6. Example of clothing with nonstandard constructional solutions inspired by photographs of nature [30]. 
clothing design is finding the answer to current utility and aesthetic needs of contemporary consumers. In any design process, the customer should be clearly defined and his or her needs should be determined by finding answers to three basic questions: for whom?, what for?, and why?

\section{References}

[1] Armstrong H.-J., Patternmaking for Fashion Design, PEARSON 2014, ISBN 978-1-29202-481-3

[2] Aldrich W., Metric pattern cutting for women's wear, Blackwell Publishing 2008, ISBN 978-1-4051-7567-8

[3] Verlag R., Schnittkonstruktionen Trachtenmode, Trachten für Fraunen, System M.Müller \&Sohn 2002, ISBN 978-3929305-64-7

[4] Warnier Claire, Women's garments, Based for tailored Suits-Coats and Trousers, ESMOD EDITIONS 2009, ISBN 978-2-909617-23-7

[5] Parafianowicz Z., Piskorska M., Standard design of women's clothing, (in polish) Tricotextil Łódź 1997.

[6] Prafianowicz Z. Clothing dictionary, (in polish) WSiP Warsaw 1995, ISBN 83-02-04388-5

[7] Nowicki E. History of Construction Methods in Clothing, (in polish) 2000 Published by Grusza Pabianice, ISBN 83908437-6-5

[8] Arnold J., Patterns of Fashion 3, The cut and construction of clothes for men and women c1560-1620, QSM MACMILLAN cop. 1985, ISBN 0-89676-083-9

[9] Arnold J., Patterns of Fashion 4, The cut and construction of linen shirts, smocks, neckwear, headwear and accessories for men and women, c1540-1660, QSM MACMILLAN 2008, ISBN 978-0-89676-262-6

[10] Fairhurst C. and others, Advances in apparel production, Woodhead Publishing Limited, 2008, ISBN 978-1-84569295-7

[11] Faust M.E., Carrier S., Designing apparel for consumers, The impact of body shape and size, Woodhead Publishing Limited, 2014, ISBN 978-1-78242-210-5

[12] Więźlak W. and others, Clothing-construction, ownership and production, (in polish) Łódź 2009, ISBN 978-83-72048666-0

[13] Zaman Z., Fashion Pattern Cutting, Bloomsbury 2014, ISBN 978-1-4081-5669-8

[14] Castro L M., Hernandez I. S., Patronaje de Moda, Ilusbooks 2013, ISBN 978-84-15227-53-3

[15] Nakamichi T., Pattern Magic, Laurence King Publishing 2005, ISBN 978-1-85669-705-7

[16] Nakamichi T., Pattern Magic 2, Laurence King Publishing 2007, ISBN 978-1-85669-706-4

[17] Nakamichi T., Pattern Magic Stretch Fabrics, Laurence King Publishing 2010, ISBN 978-1-85669-827-6

[18] Sato H., Drape Drape, Laurence King Publishing 2009, ISBN 978-1-85669-841-2

[19] Sato H., Drape Drape 2, Laurence King Publishing 2010, ISBN 978-1-78067-004-1
[20] Sato H., Drape Drape 2, Laurence King Publishing 2013, ISBN 978-1-78067-100-0

[21]lkea website (http://www.ikea.com/pl/pl/dom-poswojemu/index.html?cid=ps|p/|search_brand_lodz_geo |201601151308428387_5) access data 2016_09_25

[22] Polish Language Dictionary PWN Publishing House ,2016, ISBN:9788301173777

[23] Slack Laura. What is designing? (in polish) Published by ABE Dom Wydawniczy, Warsaw 2007, ISBN 9788392279761

[24] Pawłowski A. "Initiations. About art, design and education of designers ", (in polish) Krakow : Faculty of Industrial Forms of Jan Matejko Fine Arts Academy, 2001., ISBN 8387-651-71-0

[25] Dobrołowicz W. „Psychology of technical creativity” (in polish) Wydawnictwa Naukowo - Techniczne 1993, ISBN: 83-204-1594-2.

[26] Krick E. V. , "Introduction to the technology and technical design", (in polish) Published by NT Warsaw 1975

[27] Piotrowska J., Modernist minimalism in clothing projects, (in polish) Faculty of Material Technologies and Textile Design, Lodz University of Technology, bachelor thesis 2015/16, supervised by: dr inż. M.Owczarek

[28] Juszczak K., Scandinavian minimalism in the composition of women's clothing, , (in polish) Faculty of Material Technologies and Textile Design, Lodz University of Technology bachelor's thesis 2015/16, supervised by: $d r$ inż. M.Owczarek, dr M.Łukawska

[29] Augustyniak J., Collection of women's clothing inspired by elements coming from Scandinavian design, (in polish) Faculty of Material Technologies and Textile Design, Lodz University of Technology, master's thesis. 2015/16, supervised by: dr inż. M.Owczarek , dr M.Łukawska

[30] Wodzyńska A., Generation X - as a kind of inspiration for contemporary clothing collection; (in polish) Faculty of Material Technologies and Textile Design, Lodz University of Technology, bachelor's thesis 2015/16, supervised by: dr inz. M.Owczarek, dr A.Wereszka

[31] Miklewicz B., Post-apocalyptic fashion. Clothing collection for both sexes inspired literature, art and futurological science, WTMiWT Pt , master's thesis. 2015/16, supervised by: prof. A.Nawrot, dr inż. M.Owczarek

[32] Bryszewska P., Inspiration with selected elements of futuristic art based on non-standard construction forms, (in polish) Faculty of Material Technologies and Textile Design, Lodz University of Technology, bachelor's thesis 2015/16, supervised by: dr inż. M.Owczarek, dr M.Łukawska

[33] Małkowska A., Inspiration with the work of Zaha Hadid in creating a collection of women's clothing, WTMiWT PŁ , bachelor's thesis 2015/16, supervised by: dr inż. M.Owczarek, dr M.Łukawska

[34] Stęplewska N., Nature as an inspiration in fashion. Collection of women's clothing with the use of copyright photos, (in polish) Faculty of Material Technologies and Textile Design, Lodz University of Technology, master's thesis 2015/16, supervised by: prof. A.Nawrot, dr inż. M.Owczarek 